\title{
Effectiveness of Meditation in Relieving Anxiety among General Nursing and Midwifery Students
}

\author{
Aditi Karmakar
}

Clinical Instructor, College of Nursing, Medical College and Hospital, W.B.

\begin{abstract}
Meditation is the gathering of self knowledge and the dispelling of ignorance. It enables an individual to create new attitudes and response to life, giving a clear spiritual understanding to oneself and it has assuming importance in reducing the level of anxiety and improving quality of life, in patients as well as in general population. A study was conducted to evaluate the effectiveness of meditation in relieving anxiety among 60 numbers of second year general nursing and midwifery students based on J.W Kenney's open system model. The experimental group had undergone concentrative meditation practices half an hour daily for 21 days and analysis revealed that there was significant reduction in the state - trait anxiety in experimental group $(\mathrm{p}<0.05)$ as compared to control group but there was no association between socio- demographic data and level of anxiety.
\end{abstract}

Key Words: State - Trait Anxiety,

Concentrative meditation, General Nursing and Midwifery Students (GNM).

\section{INTRODUCTION}

Anxiety is an emotion characterized by feelings of tension, worried thoughts and physical changes. ${ }^{[1]}$. It is a feeling of apprehension and fear with physical symptoms like palpitation, sweating and feeling of stress ${ }^{[2]}$.

It can alert us to dangers and help us to prepare and pay attention. Anxiety often affects everyday life including the work place and educational setting. People should get rid off the anxiety by giving some simple effort ${ }^{[3]}$. Every individual should aware to cope up from anxiety successfully and to live a healthy life. As long as one is alive, there is always some stress- this positive stress is necessary as it motivates and gives physical strength to perform well [4]. Nursing students are in the stage of late adolescents or young adult in the developmental phase.

Adolescent of an individual is in 10 yrs -19 yrs of age group. ${ }^{[5]}$ Adolescent is in transitional age or in problem age. It has major problems of adjustment in their social relationship at home, neighbourhood and school ${ }^{[6]}$. General Nursing and Midwifery students have experienced anxiety especially from the second year of their study as because they exposed to new subjects and new clinical field especially in operation theatre and psychiatric nursing area. In addition, they are away from home.

Meditation helps in reducing the level of anxiety ${ }^{[7]}$ and the present study was conduct to determine the effectiveness of meditation on level of anxiety among $2^{\text {nd }}$ year General Nursing and Midwifery students.

\section{MATERIALS \& METHODS Design, Sample and Setting -}

For the present study, evaluative approach in which quasi experimental control group pre test - post test design was adopted. Non - probability convenience sampling technique was used to select the students ${ }^{[8]}$.

\section{Instruments and Data Collection:}

The data were selected using socio demographic data sheet. The level of anxiety among the students was measure by 
modified Speilberg's State-Trait anxiety inventory ${ }^{[9]}$. It consisted of self reported scales for measuring state and trait anxiety in which each concept contained 20 items. The data were also collected by using checklist for meditation technique and opinionnaire on meditation.

The necessary approval by the ethic committee of the two nursing schools and the consent from the individual students of the both experimental and control group had been taken before conducting the study.

Concentrative meditation was practiced among the students in experimental group for half an hour daily for 21 days. They were advised to practice the same as their own on the two off days and good compliance of the same was reported on the subsequent days.

They were also given the freedom to drop out from the programme if they wished too but no such problems were being faced during data collection procedure. The students were encouraged to listen the commentary on concentrative meditation in cassette file for 25 minutes.

\section{Steps of meditation:}

Choose the schedule place of seminar room where the students can relax without distraction or interruptions. Sit up in padmasana position comfortably keeping the back straight. Breathe in and breathe out for 10 minutes by closing the eyes. Listen the meditation commentary for 25 minutes to enhance concentration. Again breathe in and breathe out for 10 minutes. Open the eyes and relax.

\section{Data Analysis:}

Level of anxiety that is state and trait anxiety were assessed by using modified Speilberg's state and trait inventory. The state - trait anxiety scores in day -1 among the two groups were compared using independent " $\mathrm{t}$ " test. The state and trait scores on the day-1 and day-23 in experimental group were compared by paired " $\mathrm{t}$ " test. The state and trait scores of the two groups on the day- 23 were compared by using independent " $t$ " test.

\section{RESULTS}

The level of anxiety that is state and trait anxiety scores at the beginning (day-1) and end (day-23) of the meditation course for experimental and control group are given in Table $1 . n=60$

\begin{tabular}{|c|c|c|c|c|c|c|c|}
\hline \multirow[t]{2}{*}{ Phase } & \multirow[t]{2}{*}{ Group } & \multicolumn{3}{|c|}{ Effect of meditation on state anxiety } & \multicolumn{3}{|c|}{ Effect of meditation on trait anxiety } \\
\hline & & Mean & SD & t value & Mean & SD & t value \\
\hline \multirow[t]{2}{*}{ Pre meditation } & Experimental & 44.63 & 8.49 & \multirow{2}{*}{$\begin{array}{l}1.586^{*} \\
(\mathrm{NS})\end{array}$} & 42.06 & 6.361 & \multirow{2}{*}{$\begin{array}{l}0.480 * \\
(\mathrm{NS})\end{array}$} \\
\hline & Control & 41 & 8.92 & & 41.16 & 7.635 & \\
\hline \multirow[t]{2}{*}{ Post meditation } & Experimental & 35.86 & 6.125 & \multirow{2}{*}{$\begin{array}{l}4.56^{*} \\
(\mathrm{~S})\end{array}$} & 33.6 & 4.779 & \multirow{2}{*}{$\begin{array}{l}5.762 * \\
(\mathrm{~S})\end{array}$} \\
\hline & Control & 44.76 & 8.1 & & 44.26 & 8.759 & \\
\hline
\end{tabular}

Table-2 shows the state and trait anxiety scores in pre test -post test phases among experimental and control group. $n=60$

\begin{tabular}{|c|c|c|c|c|c|c|c|}
\hline \multirow[t]{2}{*}{ Group } & \multirow[t]{2}{*}{ Phase } & \multicolumn{3}{|c|}{ Effect of meditation on state anxiety } & \multicolumn{3}{|c|}{ Effect of meditation on trait anxiety } \\
\hline & & Mean & SD & t value & Mean & SD & t value \\
\hline \multirow[t]{2}{*}{ Experimental } & Pre meditation & 44.63 & 8.49 & \multirow{2}{*}{$\begin{array}{l}4.588^{*} \\
(\mathrm{~S})\end{array}$} & 42.06 & 6.361 & \multirow{2}{*}{$\begin{array}{l}5.824 * \\
(\mathrm{~S})\end{array}$} \\
\hline & Post meditation & 35.86 & 6.125 & & 33.6 & 4.779 & \\
\hline \multirow[t]{2}{*}{ Control } & Pre meditation & 41 & 8.92 & \multirow{2}{*}{$\begin{array}{l}1.684^{*} \\
\text { (NS) }\end{array}$} & 44.16 & 7.655 & \multirow{2}{*}{$\begin{array}{l}1.459^{*} \\
\text { (NS) }\end{array}$} \\
\hline & Post meditation & 44.76 & 8.1 & & 44.26 & 8.759 & \\
\hline
\end{tabular}

\section{DISCUSSION}

From the Table-1, it is clear that there is no significant changes among experimental and control groups in both state and trait level of anxiety in pre meditation phase. But in post meditation phase, there are significant changes in state and trait level of anxiety among both the groups. So, it concludes that concentrative meditation brings changes in state and trait anxiety scores in post meditation phase in experimental group.

The findings of our study are in concordance with the findings, revealing that yoga and relaxation therapy causes significant improvement in attention deficit 
hyperactivity disorder (ADHD) along with anxiety disorder. ${ }^{[10]}$ Similarly, impact of Heartfulness Meditation on reducing stress in nursing students has also been reported. [11]

From the above Table- 2, it was found that significant changes in experimental group in state and trait anxiety while in the control group, there is no such significant changes found in state and trait anxiety level.

It was also observed that meditation was an effective intervention for nursing students to decrease their stress and anxiety and could be used to manage stress in student nurses ${ }^{[12,13]}$.

The study reveals that there is no significant association between state and trait anxiety with selected demographic variables like age, family history of psychiatric problems, psychological problems and physical problems. Students also express the usefulness of concentrative meditation in day to day life.

\section{Recommendations:}

A comparative study can be done to compare the effectiveness of meditation and other relaxation techniques.

A large number of samples can be included in the study.

Other variables like study habits, academic performance etc can be included in the study.

\section{Nursing Implication:}

Practice of meditation helps in attention regulation, improving concentration and memory along with reducing anxiety. While delivering care to the patients, nursing personnel may introduce meditation which helps in providing holistic care to the patient and by practicing themselves nurse can also overcome the stress.

Nurse administrator can take quick decision and able to reasoning the decision in correct pathway.

\section{CONCLUSION}

This preliminary observation suggests that the practice of meditation leads to remarkable relieving of level of anxiety of students and can therefore make an appreciable contribution to lead a happy and healthy life in students as well as in general population.

\section{Acknowledgement: None}

\section{Conflict of Interest: None}

\section{Source of Funding: None}

\section{Ethical Approval: Approved}

\section{REFERENCES}

1. American Psychological Association, Definition of Anxiety.[cited January 2020]. Available : $\quad$ http://www.medical newstoday.com

2. American Psychiatric Association, Definition of Anxiety.[cited January 2017]. Available:http://www.psyciatry.org>patients -families/anxietydisorder.

3. Keable D . Management of Anxiety: A guide for therapist, $3^{\text {rd }}$ Edition. London: M/S Churchill Livirgstene 2008.

4. Behere, ShashankP., Richa Yadav and Prakash B. Behere. "A comparative study of stress among students of medicine, engineering and nursing." Indian Journal of Psychological Medicine. 2011; 33(2): 145.

5. World Health Organization. WHO Definition of Adolescents.[cited May 2020]. Available : http://www.who.int.home.health topic.

6. Sancar B, Yalcin AS, Acikgoz I. An examination of anxiety levels of nursing students caring for patients in terminal period. Pakistan Journal of Medical Sciences 2018; 34(1): 94-99.

7. Breedvelt J, Amanvermez Y, Karvotaki E and Ebert D. The effects of meditation, yoga and mindfulness on depression, anxiety and stress in tertiary education students: A meta analysis. Frontiers in Psychiatry 2019.http://doi.org/10.3389/fpsyt 2019.00193.

8. Polit Denise F, BECK Cheryl T, Essentials Nursing Research appraising Evidence for Nursing practice, $8^{\text {th }}$ Edition, 2013, 
Lippincott Williams \&Wilkins. Page 100 110.

9. Speilbeger C.D, Sarason I.G(1975). State Trait Anxiety Inventory. USA: Hemisphere Publishing Corporation.

10. Jenson $\mathrm{P}$ and Kenny d.T. relation between yogic exercise and ADHD. Journal of Attention Disorder. 2004;7(4):205- 216.

11. Raja Amarnath G, Raja Marimuthu S, Jenitha S, Rajan C, Karumari S and Patel S. Impact of Heartfulness Meditation on Reducing Stress in nursing Students : A Prospective Observational Study. International Journal of Medical Research \& Health Sciences. 2018;7(1):98-109.

12. Yu-Feng li, Wen- Xin Sun, xiu-jie Sun, Juan Sun, Dong - Mei Yang, Bei - Li Jia and Bin Yuan. Effects of mindfulness meditation on anxiety, depression, stress and mindfulness in nursing students: a meta-analysis and trial sequential analysis of randomized controlled trials. Frontiers of Nursing. 2020; 7 (1): 5969. DOI: https://doi.org/10.2478/fon-2020-0001

13. Kang Y.S, Choi S.Y and Ryu E. The effectiveness of a stress coping programme based on mindfulness meditation on the stress, anxiety and depression experienced by nursing students in Korea. Nurse Educ Today. 2009 Jul;29(5):538-43. DOI: 10.1016/j.nedt.2008.12.003

How to cite this article: Karmakar A. Effectiveness of meditation in relieving anxiety among general nursing and midwifery students. International Journal of Research and Review. 2021; 8(6): 320-323. DOI: https://doi.org/10. 52403/ijrr.20210640 